\title{
Return migration and the age profile of retirement among immigrants
}

\author{
Deborah A Cobb-Clark ${ }^{1 *}$ and Steven Stillman ${ }^{2}$
}

\author{
* Correspondence: \\ d.cobb-clark@unimelb.edu.au \\ ${ }^{1}$ Melbourne Institute of Applied \\ Economic and Social Research, \\ University of Melbourne, Parkville, \\ VIC 3010, Australia \\ Full list of author information is \\ available at the end of the article
}

\begin{abstract}
We analyze the relationship between the age profile of retirement within an immigrant population and aggregate return migration rates for individuals from different countries of origin. The latter serves as a proxy for the relative net benefits of return migration to that origin country. Our simple theoretical model illustrates that under reasonable conditions the probability of return migration is maximized at retirement. This implies that different immigrant populations will have different retirement profiles, not only because individual retirement behavior differs, but also because the propensity for return migration varies. Consistent with our theoretical model, we estimate a negative relationship between immigrants' retirement status and the aggregate return migration rate of their fellow countrymen. As theory suggests, this link is strongest for immigrants who are near the retirement age.
\end{abstract}

JEL codes: J260, J010, J080

Keywords: Retirement; Immigrants; Return migration; Emigration; Australia

\section{Introduction}

In the coming decades, many countries are expected to experience dramatic increases in the fraction of their populations over the age of 65 and relative falls in the share of their working-age populations (Anderson and Hussey 2000; Bijak et al. 2007; Gruber and Wise 2001). The resulting increase in the demand for health care and old-age pensions-in the face of a more or less constant tax base-has left governments searching for strategies to cope with the anticipated fiscal pressures stemming from population aging. Whether or not increased immigration might reverse the trend toward population aging and increasing dependency ratios has been hotly debated. In 2001, the United Nations undertook a major study of the 'replacement migration' question and concluded that it was extremely unlikely that the magnitude of the immigration flow necessary to prevent ageing in most countries could ever be achieved (United Nations (UN) 2001). Since then, most experts have come to agree that immigration alone cannot provide a long-term, permanent solution to the effects of population aging since immigrants will also age and generate their own fiscal pressure (Bermingham 2001; Bijak et al. 2007; Boersch-Supan 2003; Holzmann 2005; Rendall and Ball 2004).

Ultimately, however, the effect of immigration on the economic activity and demographic structure of host countries will depend heavily on immigrants' retirement decisions and return migration patterns. Host countries will experience lower costs associated with old-age pensions and health care if immigrants work while they are young, but then delay their retirement or choose to return home in their old age ${ }^{1}$.

\section{Springer}

(C) 2013 Cobb-Clark and Stillman; licensee Springer. This is an open access article distributed under the terms of the Creative Commons Attribution License (http://creativecommons.org/licenses/by/2.0), which permits unrestricted use, distribution, and reproduction in any medium, provided the original work is properly cited. 
Unfortunately, we know almost nothing about the labor market behavior of older immigrant workers-despite an explosion of research analyzing retirement decisions more generally. Moreover, although return migration occurs frequently, we also know very little about how the economic activity of temporary and permanent migrants might differ. $^{2}$

This paper fills a void in the literature by investigating the relationship between an immigrant's decision whether to retire and whether to return to their country of origin. The ideal approach to examining this question would be to jointly examine these decisions at the individual level using longitudinal data that followed individuals in a representative sample both over time and across national boundaries. Unfortunately, we know of no data source that meets this criteria. Instead, in this paper, we sketch out a simple theoretical model of emigration decisions that allows us to make empirical predictions about the relationship between aggregate retirement rates for immigrants from different origin countries resident in a host country and the net benefits of returning to that origin country. This model illustrates that under reasonable conditions the probability of return migration is maximized at retirement. Despite a large, mainly theoretical, literature analyzing the return migration decision (see Dustmann and Weiss 2007 for a review), the effect of retirement on immigrants' incentives to return home have been completely overlooked.

Using this framework and data on immigrants in the Household, Income and Labour Dynamics in Australia (HILDA) Survey, we then examine the relationship between the age profile of retirement within the immigrant population and aggregate return migration rates for individuals from different countries of origin, which we argue serves as an ideal proxy for the relative net benefits of return migration to that country. In addition, we examine whether, as hypothesized by our model, this link is strongest for those individuals who are closest to the retirement age. Australia is a particularly attractive country for studying the relationship between retirement and return migration, because nearly one in four individuals in the Australian population is foreign-born (Australian Bureau of Statistics ABS 2007a) and, unlike the case in most countries, accurate data on return migration rates for individuals from different countries of birth are available.

We do not attempt to estimate a behavioral model of individual immigrants' retirement and return migration decisions because, like other major panel data sets, the HILDA data do not follow individuals who migrate outside Australia. Moreover, while HILDA provides longitudinal data on retirement status for over 2,000 immigrants age 45 and above, only 136 retire during the first five waves which we use for our analysis. Hence, it would not be possible to estimate a properly specified behavioral model that controls for unobserved heterogeneity in tastes for leisure. It is important to emphasize that the theoretical model we sketch out can be estimated using aggregate data on agespecific retirement rates for immigrants from different countries of origin along with information on aggregate return migration rates from Australia to these countries, which is something that we do below. The only advantage to extending our analysis to the individual level is that it allows us to control for other characteristics that might be correlated with both aggregate retirement rates and return migration rates for individuals from different country of origins, most importantly the average number of years that immigrants from different origin countries have resided in Australia. ${ }^{3}$ 
Consistent with our theoretical model, we estimate a negative relationship between immigrants' retirement status and the return migration rate of their fellow countrymen, i.e. immigrants from countries with higher return migration rates are less likely to be observed to be retired in Australia compared to immigrants from countries with lower return migration rates. As theory suggests, this link is strongest for immigrants who are at (or near) the retirement age. Overall, there is a much closer link between return migration and the retirement status of immigrant men suggesting that for women return migration may be a family rather than individual decision.

\section{The previous literature: return migration and immigrant retirement}

The economics literature on return migration has been primarily concerned with understanding the incidence and optimal timing of this decision (Hill 1987; Stark et al. 1997; Dustmann and Kirchkamp 2002; Dustmann 2003b). While immigration itself typically stems from superior economic opportunities in the host country, immigrants' return migration is assumed to be driven by preferences for (or lower costs of) consumption at home (Hill 1987; Djajić 1989; Dustmann 1997b; Stark et al. 1997) or concerns for one's children (Dustmann 2003a). The potential for return migration has important consequences for immigrants' host-country decisions regarding work effort (Djajić 1989; Galor and Stark 1991), labor market participation (Dustmann 1997a), savings behavior (Galor and Stark 1990; Dustmann 1997b; Stark et al. 1997), and human capital investments (Dustmann 1999, 2008).

For example, immigrants who anticipate returning home to relatively unfavorable economic conditions are expected to have higher participation rates and to work harder than either permanent immigrants or the native-born (Galor and Stark 1991; Dustmann 1997a). Temporary migration may also reduce the incentives for human capital investment (Dustmann 1999, 2008), but increase the incentives for remittances (Merkle and Zimmermann 1992). Finally, the effect of re-migration on savings behavior depends on the wage differential and relative risk in the host and home countries (Dustmann 1997b). ${ }^{4}$

Difficulties in measuring return migration have limited empirical analyzes of this process. As Dustmann and Weiss (2007) note, "there are typically no procedures in place that register immigrants who leave a country". At the macro level, this leaves researchers attempting to combine information from various censuses and surveys to infer the numbers (and characteristics) of immigrants who appear to have emigrated (e.g. Dustmann and Weiss 2008). At the micro level, researchers often rely on immigrants' stated intentions regarding return migration to understand how the behavior of temporary and permanent migrants differs. The general conclusion is that immigrants who intend to emigrate both save and remit more than immigrants who intend to remain permanently in the host country (Merkle and Zimmermann 1992; Sinning 2011; Bauer and Sinning 2011).

Previous research has not studied the link between immigrants' intentions to emigrate and the timing of their retirement-though it seems reasonable to expect one. Moreover, given the importance of wage differentials in economic models of the migration decision, it is surprising that theoretical models do not consider retirement as one of the incentives for return migration. ${ }^{5}$ The empirical evidence certainly suggests that 
many immigrants anticipate either returning to their home country or moving frequently between the home and host countries after retirement (De Coulon and Wolff 2006) . $^{6}$ There is also evidence that older immigrant workers are more likely to become return migrants (Constant and Massey 2002). In what follows, we illustrate the theoretical effect of retirement in raising the incentives for immigrants to leave the host country and return home. We subsequently assess the effect that the level of return migration has on the age profile of retirement in the immigrant population.

\section{Theoretical framework and estimation model}

\subsection{Modeling the effect of retirement on return migration}

We begin by developing a simple model of the net benefit of return migration concentrating on immigrants' decisions about where (rather than how much) to work ${ }^{7}$. Immigrants decide whether or not to return to their country of origin on the basis of the total future consumption achievable in the two countries until the end of life. The model is static and we do not account for either uncertainty in-or the trajectory of-wages, prices, or consumption over time. This simple approach allows us to abstract from unnecessary complexity.

Our main interest is in understanding how retirement affects the incentives for return migration. An individual's retirement date is assumed to be determined outside the model, perhaps as a result of institutional arrangements that define the age at which he or she may access either public or employer-provided pension benefits. Immigrants save throughout their working lives to fund consumption in retirement. We assume that there are fixed costs associated with return migration, for example retirement savings may only be partially portable and thus transferring them to the origin country may involve a loss of benefits. Finally, we assume that immigrants' preferred bundle of consumption goods is constant across countries, but that it is less costly in the origin than in the host country (see Stark et al. 1997; Dustmann and Kirchkamp 2002). ${ }^{8}$

Time is continuous in the model. Immigrants begin their lives in at $t=0$ in the host country and die at $t=1$. Retirement occurs at time $\tau$ with $0<\tau<1$. Consider first the savings process. In the period prior to retirement, immigrants save a portion of their earnings to fund post-retirement consumption. Accumulated retirement savings at time $t$ are then given by:

$$
S_{t}=(1-R)\left[t\left(w^{H}-c^{H}\right)\right]+R\left[\tau\left(w^{H}-c^{H}\right)-(t-\tau) c^{H}\right]
$$

where $w^{H}$ denotes host-country wages, $c^{H}$ is the consumption level in the host country, and $\mathrm{R}$ is an indicator variable that takes the value 0 in the pre-retirement period $(t<\tau)$ and 1 in the post-retirement period $(t \geq \tau)$. In the pre-retirement period $(R=0)$, savings are equal to total earnings minus total consumption to date. In the post-retirement period $(R=1)$, savings equal the total savings accumulated at retirement minus any post-retirement consumption. Consumption levels are chosen so as to exhaust any savings at the end of life.

Following others in the literature (e.g. Dustmann 1997a, 2008; Dustmann and Kirchkamp 2002), we assume that at each period $t=t^{*}$ immigrants make a decision whether or not to leave the host country and return home. Immigrants benefit from return migration if their accumulated retirement savings and future earnings afford a higher standard of living in the origin country than in the host country. Specifically, the net benefit to return migration at time $t^{*}$ is given by the difference in future total consumption achievable in the two countries. Given that we assume that there are no 
bequests and all resources are exhausted at death, this implies that future consumption over one's remaining life time is equivalent to future resources. Immigrants are assumed to emigrate whenever the net benefits from doing so are positive. Return migration occurs, therefore, if and only if

$$
N B_{t^{*}}=\Pi_{t^{*}}^{O}-\Pi_{t^{*}}^{H}>0
$$

where $\Pi_{t^{*}}^{O}$ and $\Pi_{t^{*}}^{H}$ are the future resources available at time $t^{*}$ if immigrants do and do not choose to return migrate, respectively. More specifically, the net benefit to return migration at time $t^{*}$ can be written in terms of accumulated savings and any future earnings over one's remaining career as follows

$$
N B_{t^{*}}=\frac{1}{p}\left\{S_{t^{*}}+\left(\tau-t^{*}\right) w^{O}(1-R)-\bar{C}\right\}-\left\{S_{t^{*}}+\left(\tau-t^{*}\right) w^{H}(1-R)\right\}
$$

where $w^{O}$ captures origin-country wages, $\bar{C}$ represents fixed costs (e.g. the loss of pension benefits, travel costs, etc.) associated with return migration ${ }^{9}$. The host-country price level is normalized to 1 and relative origin-country prices are given by $p$. We assume $w^{O}<w^{H}$ and $p<1$ implying that although economic opportunities are better in the host country than in the origin country, immigrants' preferred consumption bundle is less expensive at home.

The net benefit to return migration will be positive at time $t^{\prime \prime}$ if the resources available for consumption over an immigrant's remaining life time are higher in the origin country than in the host country. The last term in equation (3) reflects the total resources available if an immigrant decides to remain in the host country. Total resources include retirement savings accumulated to time $t^{*}$ while working in the host country as well as an immigrant's earnings over his or her remaining working life in the host country. Post-return resources levels are given by the first term on the right-hand side of equation (3). Although accumulated savings are the same $\left(S_{t^{*}}\right)$, future resources will be lower in the origin country because $w^{O}<w^{H}$ and because return migrants must also pay the fixed costs associated with return migration $(\bar{C})$. At the same time, each dollar of resources funds more consumption in the origin country because prices $(p)$ are lower. Consistent with other models in the literature (Djajić 1989; Dustmann 1997b; Stark et al. 1997), remigration may occur despite persistently higher host-country wages because consumption is less expensive in the origin country.

How does retirement affect the probability of return migration? To address this question, we consider the way in which the incentives for return migration change over time both before and after retirement. In the post-retirement period $\left(t^{\prime \prime} \geq \tau\right)$, immigrants choose to return to their country of origin if and only if

$$
M_{t^{*}}=I\left(\frac{(1-p) S_{t^{*}}-\bar{C}}{p}>0\right)
$$

where $I$ denotes a simple indicator function and $M$ reflects the return migration decision. Substituting accumulated savings as given by Equation (1) and rearranging implies that

$$
\begin{aligned}
M_{t^{*}} & =I\left((1-p) S_{t^{*}}>\bar{C}\right) \\
& =I\left((1-p)\left[S_{R^{-}}-\left(t^{*}-\tau\right) c^{H}\right]>\bar{C}\right)
\end{aligned}
$$


Hence, after retirement, return migration occurs if the costs of return migration $(\bar{C})$ are less than the additional consumption made possible by consuming one's remaining savings in the origin country where prices are lower. Equation (5) implies that the change in the probability of return migration over time in the post-retirement period is given by:

$$
\frac{\partial \operatorname{Pr}(M=1)}{\partial t^{*}}=-(1-p) c^{H}
$$

Before retirement (i.e. in periods $t^{\prime}<\tau$ ), however, immigrants also take into account the effect that return migration will have on their future earnings. Given the net benefit to return migration shown in Equation (3), immigrants choose to return migrate in the pre-retirement period if and only if

$$
M_{t^{\prime}}=I\left(\frac{S_{t^{\prime}}+\left(\tau-t^{\prime}\right) w^{O}-\bar{C}-p\left[S_{t^{\prime}}+\left(\tau-t^{\prime}\right) w^{H}\right]}{p}>0\right)
$$

Substituting accumulated savings and rewriting implies that immigrants choose to return migrate in the pre-retirement period whenever:

$$
\begin{aligned}
M_{t^{\prime}} & =I\left(S_{t^{\prime}}+\left(\tau-t^{\prime}\right) w^{O}-p S_{t^{\prime}}+p\left(\tau-t^{\prime}\right) w^{H}>\bar{C}\right) \\
& =I\left((1-p) S_{t^{\prime}}-\left(\tau-t^{\prime}\right)\left(p w^{H}-w^{O}\right)>\bar{C}\right) \\
& =I\left((1-p) t^{\prime}\left(w^{H}-c^{H}\right)-\left(\tau-t^{\prime}\right)\left(p w^{H}-w^{O}\right)>\bar{C}\right)
\end{aligned}
$$

Immigrants return migrate before retirement only if the advantages of consuming one's accumulated savings in the origin country outweigh both the cost of return migration and the earnings loss associated with returning to a low-wage labor market. Thus, the change in the probability of return migration over the pre-retirement period is given by:

$$
\frac{\partial \operatorname{Pr}(M=1)}{\partial t}=\left(w^{H}-w^{O}\right)-(1-p) c^{H}
$$

There are several things to note about these changes over time. First, the probability of remigration declines over the post-retirement period so long as consumption in the origin country is less expensive than in the host country (i.e. $p<1$ ) (see Equation (6)). Every year that return migration is delayed involves a loss associated with consuming in the higher price market which is no longer being compensated by higher wages. In the pre-retirement period, the probability of return migration increases every year so long as the wage advantage afforded by the host country dominates the higher living costs. This will be true whenever there is a positive economic return to immigration to the host country in the first place. Together these relationships imply that the probability of return migration is maximized at the point of retirement when the wage advantage of the host country relative to the origin country is no longer relevant and the consumption benefits of moving one's retirement savings to the lower cost country are maximized.

\subsection{Return migration rates and the retirement status of immigrant populations}

The simple model discussed above is useful in highlighting how the incentives for return migration change when retirement occurs and higher relative wages are no longer 
a factor in immigrants' decisions about whether to stay or to return home. We now show how this interdependence between emigration and retirement affects the aggregate retirement status of the remaining immigrant population and then link this directly to the empirical models that we estimate.

Note that the probability that an immigrant $i$ from sending country $j$ retires in the host country is given by the joint probability:

$$
\begin{aligned}
\operatorname{Prob}\left(R_{i j}=1, M_{i j}=0\right) & =\operatorname{Prob}\left(M_{i j}=0 \mid R_{i j}=1\right) \operatorname{Prob}\left(R_{i j}=1\right) \\
& =\left[1-\operatorname{Prob}\left(M_{i j}=1 \mid R_{i j}=1\right)\right] \operatorname{Prob}\left(R_{i j}=1\right)
\end{aligned}
$$

where, as before, $R$ and $M$ are indicator variables for being in the post-retirement period and having return migrated, respectively. Equation (10) demonstrates that there is a negative relationship between the probability that remaining immigrants are retired and the probability of emigrating in the post-retirement period. In the limit, when return migration to country $j$ is nearly universal, none of the immigrants from country $j$ remaining in the host country will be retired. This implies that different immigrant populations will have different retirement profiles, not only because individual retirement behavior differs, but also because variation in sending-country wages or price levels lead to differing propensities of return migration.

\subsection{Estimation model}

To empirically analyze the relationship between country-specific return migration rates and the pattern of retirement, we estimate reduced-form models of retirement status controlling for country of birth-specific emigration rates, which proxy for the net benefits of emigration for immigrants in HILDA from different countries since they reflect the prior migration decisions made by one's countrymen. In some models, we also control for individuals' demographic and human capital characteristics. Including controls for characteristics that are potentially related to retirement status, such as age, years in Australia, education, and work experience, allows us to account for the effect that differences in the composition of immigrant populations from different countries of origin plays in explaining the relationship between country of birth-specific emigration rates and retirement status. Since our objective is not to estimate a behavioral model of the retirement decision, but rather to understand the way that the propensity to be retired at a point in time (i.e. retirement status) differs among individuals from different countries of birth, we adopt a cross-sectional estimator, pooling data from multiple survey waves to improve efficiency.

We assume that an individual's propensity to be retired $\left(R_{i}^{*}\right)$ can be expressed as:

$$
R_{i j}^{*}=X_{i j} \beta+Z_{j} \phi+\varepsilon_{i j}
$$

where $X_{i j}$ captures demographic and human capital characteristics, $Z_{j}$, is the aggregate emigration rate over the previous five years for each sending country (see Section 4.2) and $\varepsilon_{i j}$ is a random error term. Emigration rates are calculated using administrative data and capture the cross-national variation in institutional arrangements, price levels, etc. that underlie the aggregate costs and benefits of emigration for individuals from each 
specific origin country. The simple theoretical model discussed above shows that we should expect to find a negative relationship between country-specific emigration rates and the propensity for any individual immigrant to report being retired.

The propensity to be retired is unobserved, so we create an indicator variable reflecting actual retirement status. Specifically,

$$
\operatorname{Pr}\left(R_{i j}=1\right)=\operatorname{Pr}\left(X_{i j} \beta+Z_{j} \phi+\varepsilon_{i j}>0\right)=\Phi(Q \gamma)
$$

where $\mathcal{Q}=\left(X_{i j}, Z_{j}\right), \gamma=(\beta, \phi)$, and $\Phi$ is the standard normal cumulative density function. Finally, we assume that $\varepsilon_{i j} \sim N(0,1)$, is independent of the explanatory variables in equation (12) and is potentially clustered for individuals from the same country of birth $j .{ }^{10}$

\section{The data}

\subsection{The household income and labour dynamics survey}

The main data source used for the analyzes in this paper is the Household Income and Labour Dynamics in Australia (HILDA) Survey which collects longitudinal information from a nationally-representative sample of more than 7,600 Australian households encompassing almost 20,000 individuals aged 15 and older (see Wooden, et al. 2002). As 22.1 percent of the Australian population is foreign-born (Australian Bureau of Statistics ABS 2007a), the HILDA sample includes a large number of immigrants from a range of origin countries (88, in fact). Moreover, while many studies of retirement behavior are based only on samples of older individuals, each nonemployed HILDA respondent aged 45 and over is asked about his or her retirement status. ${ }^{11}$ The ability to measure retirement status among several cohorts of foreignborn workers from different countries of birth makes HILDA data well suited to examine the relationship between the propensity of return migration and retirement status.

We pool the first five waves of HILDA data covering the years 2001 to 2005 to examine the retirement status of foreign-born men and women over the age of 45 . We have made a number of necessary sample restrictions. Specifically, individuals under the age of 45 were not asked the retirement questions and have been dropped from the sample. We then drop a small number of individuals who either have never worked or are missing information for retirement status or other key variables of interest. This leaves us with a main estimation sample of 1,122 immigrant men and 1,032 immigrant women. ${ }^{12}$ Each individual provides, on average, 3.6 waves of data, leading to 7,798 observations in our estimation sample. Details about sample individual characteristics for the analysis sample along with a comparison sample of the Australian-born are presented in Additional file 1.

\subsection{The probability of return migration}

Although most countries do not systematically collect detailed information on emigrants (see Dustmann and Weiss 2008), Australia is an exception. Australia's geography means that all individuals entering or leaving the country do so through one of only seven international airports. Moreover, each person entering or leaving Australia is required to provide the Australian Department of Immigration and Citizenship (DIAC) with a completed Incoming or Outgoing Passenger declaration at the airport. These 
cards are legal documents and there are penalties for not filling them out completely or for making false statements. The data obtained from these cards are then matched to the personal information obtained from an electronic swipe of the person's passport. $^{13}$

We use the published statistics on permanent departures calculated from these data (Department of Immigration and Citizenship 2007) along with census information (ABS undated) to calculate a country-specific emigration rate for 1996-2001 $\left(M_{j}^{96-01}\right)$ for all 88 countries of births represented in HILDA as follows:

$$
M_{j}^{96-01}=\frac{E_{j}^{96-01}}{E_{j}^{96-01}+P_{j}^{01}}
$$

where $E_{j}^{96-01}$ is the total number of individuals born in country $j$ who permanently left Australia between 1996 and 2001 and $P_{j}^{01}$ is the number of individuals enumerated in the 2001 Australia census who were born in country $j$. The denominator of the ratio in equation (13) reflects the population of individuals from country $j$ who would have resided in Australia in 2001 in the absence of emigration.

Information about both the weighted (by sample size) and unweighted densities of emigration rates are provided in Figure 1. The emigration rate of immigrants to Australia ranges from 0.005 (Italy) to 0.090 (Hong Kong) ${ }^{14}$. Immigrants from China, New Zealand, and Hong Kong have relatively high return migration rates, while immigrants from countries such as Italy, India and Germany are more like to remain in Australia. Emigration rates are plotted on a log-scale in each graph and, as can be seen in the unweighted results, the distribution across countries in approximately lognormal. Thus, we use a log-normal functional form for the emigration rate in all our

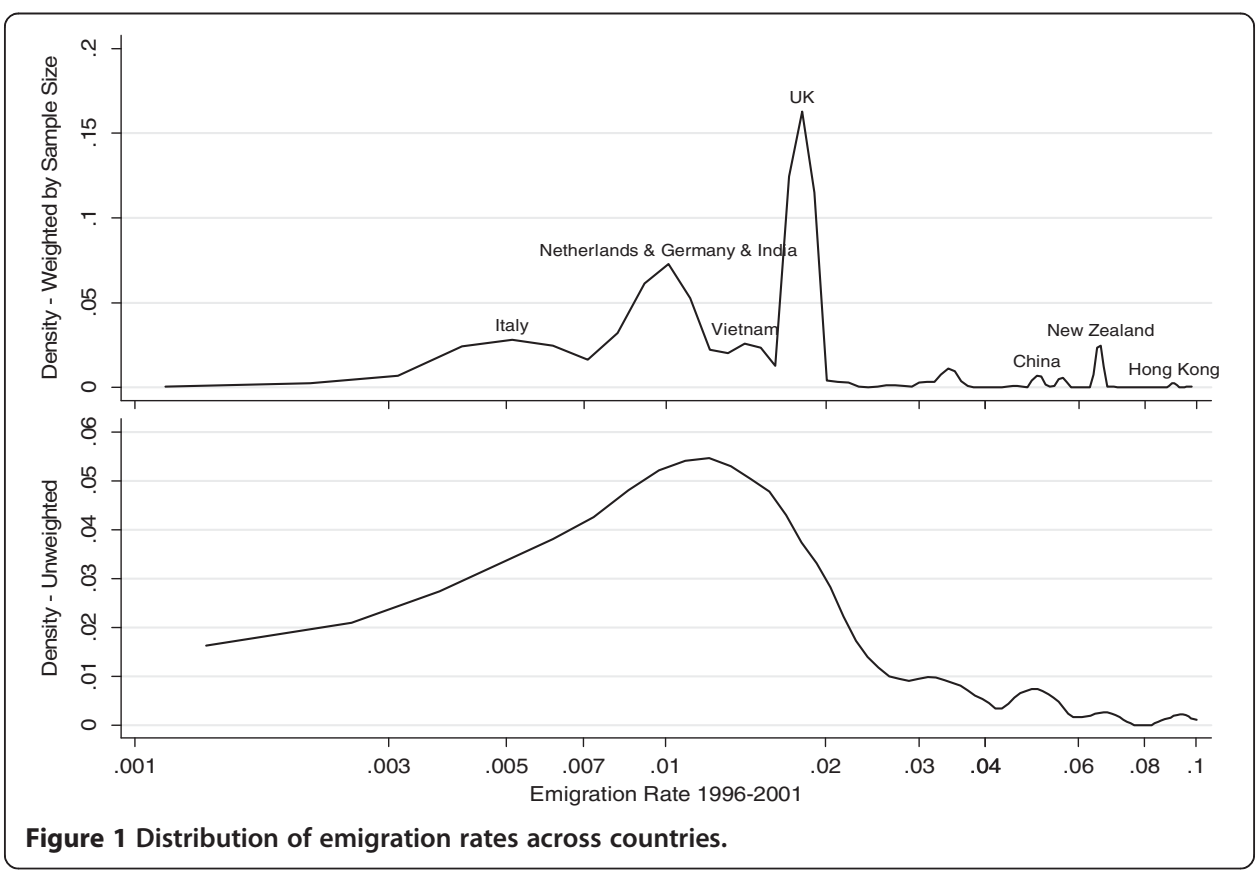


descriptive results and regression analyzes. In all cases, this provides a better model fit than when we treat the emigration rate as a linear variable.

\subsection{The timing of retirement among immigrants}

We begin by examining the mean age, years in Australia and declared retirement status of the immigrants in our sample. The first column in Table 1 presents the results for the overall sample, while the remaining columns highlight the results for the five countries that each make up more than 4 percent of the foreign-born population in HILDA (in order of importance: UK; New Zealand; Italy; Germany; Netherlands) and four important Asian countries (China; Vietnam; India and Hong Kong). Overall, 43 percent of the men in our sample and 51 percent of the women are retired. For men aged 65 and above and women aged 59 and above, the figures are 91 and 89 percent, respectively.

Our theoretical model predicts that as the net benefits of return migration increase, the proportion of the immigrant population that chooses to remain in Australia after retirement falls. Hence, we expect immigrants from countries with high return migration rates to be on average younger and less likely to be retired. Examining the results for the nine countries highlighted in Table 1, this general pattern emerges. For example, immigrant men from New Zealand, China, Hong Kong, and Vietnam are in their mid-fifties on average, while immigrant men from other source countries are, on average, in their earlysixties. Interestingly, the relationship between immigrants' average age and the length of time they have spent in Australia is not straight-forward. Although immigrant women from India and Hong Kong have both been in Australia for approximately three decades on average, the average age of women from India (60.5) is substantially higher than that of women from Hong Kong (54.4). These differences point to the importance of carefully accounting for age and years since migration in our estimation models.

We further investigate the links between average age, retirement status and emigration rates by plotting country-specific retirement rates for HILDA respondents aged 45 plus and the proportion of the immigrant population from each origin country aged 65 plus, as measured in the 2006 Census (Australian Bureau of Statistics ABS 2007b), against emigration rates (see Figures 2 and 3). The size of the plot circles in Figure 2 are proportional to the HILDA sample size for men/women from each origin country and the solid line in each graph is the best linear fit of the data (and the regression equation corresponding to this line is presented above the graph), with each point weighted by the HILDA sample size for men/women from each origin country. The plot circles and solid line are similarly defined in Figure 3 with the exception that we weight by origin-specific total immigrant population size since our independent variable in this figure is based on Census data.

These figures indicate that, as predicted by our theoretical model, there is a large, negative, and significant relationship between a country's return migration rate and the fraction of that country's immigrant population in Australia that is either retired or over age 65. For example, only 12.2 percent of men and 35.3 percent of women from New Zealand aged 45 plus are retired compared to 58.2 percent of men and 71.2 percent of women from Italy. Likewise, less than 10 percent of the New Zealand-born population in Australia is aged 65 plus, while over 50 percent of the Italian-born population in Australia is in this age-group. 
Table 1 Emigration rates, age distribution, years in Australia and percent retired by gender and country of birth

\begin{tabular}{|c|c|c|c|c|c|c|c|c|c|c|}
\hline & All immigrants & Italy & Netherlands & Germany & India & Vietnam & UK & China & New Zealand & Hong Kong \\
\hline Emigration rate & 0.020 & 0.005 & 0.009 & 0.010 & 0.011 & 0.014 & 0.018 & 0.050 & 0.065 & 0.090 \\
\hline \multicolumn{11}{|c|}{ Men } \\
\hline \multirow[t]{2}{*}{ Mean age } & 60.5 & 63.9 & 62.8 & 63.1 & 55.9 & 54.4 & 62.0 & 56.0 & 54.5 & 54.5 \\
\hline & $(0.17)$ & $(0.63)$ & $(0.67)$ & $(0.58)$ & $(1.20)$ & $(0.86)$ & $(0.28)$ & $(1.41)$ & $(0.49)$ & $(1.34)$ \\
\hline \multirow[t]{2}{*}{ Mean years in Australia } & 34.3 & 43.8 & 43.5 & 43.6 & 24.7 & 17.4 & 37.3 & 14.2 & 28.5 & 19.3 \\
\hline & $(0.24)$ & $(0.56)$ & $(0.72)$ & $(0.80)$ & $(1.37)$ & $(0.69)$ & $(0.40)$ & $(1.37)$ & $(0.81)$ & $(1.70)$ \\
\hline \multirow[t]{2}{*}{ Percent retired } & 0.426 & 0.582 & 0.538 & 0.485 & 0.218 & 0.350 & 0.452 & 0.224 & 0.123 & 0.242 \\
\hline & $(0.008)$ & $(0.031)$ & $(0.035)$ & $(0.036)$ & $(0.047)$ & $(0.054)$ & $(0.013)$ & $(0.060)$ & $(0.021)$ & $(0.076)$ \\
\hline \multirow[t]{2}{*}{ Percent retired age $>64$} & 0.907 & 0.959 & 0.847 & 0.784 & NA & NA & 0.934 & NA & 0.581 & NA \\
\hline & $(0.008)$ & $(0.018)$ & $(0.039)$ & $(0.044)$ & & & $(0.010)$ & & $(0.090)$ & \\
\hline Observations & 4,055 & 251 & 199 & 198 & 78 & 80 & 1,541 & 49 & 253 & 33 \\
\hline Individuals & 1,122 & 70 & 49 & 51 & 24 & 29 & 391 & 16 & 72 & 11 \\
\hline Percent of immigrants & & $6 \%$ & $4 \%$ & $5 \%$ & $2 \%$ & $3 \%$ & $35 \%$ & $1 \%$ & $6 \%$ & $1 \%$ \\
\hline \multicolumn{11}{|c|}{ Women } \\
\hline \multirow[t]{2}{*}{ Mean age } & 60.0 & 61.1 & 62.0 & 61.6 & 60.5 & 51.4 & 61.9 & 59.9 & 57.7 & 54.4 \\
\hline & $(0.18)$ & $(0.68)$ & $(0.77)$ & $(0.76)$ & $(1.28)$ & $(0.56)$ & $(0.30)$ & $(1.23)$ & $(0.58)$ & $(1.77)$ \\
\hline \multirow[t]{2}{*}{ Mean years in Australia } & 34.9 & 42.4 & 45.4 & 46.0 & 30.3 & 17.1 & 37.3 & 18.0 & 27.7 & 29.8 \\
\hline & $(0.24)$ & $(0.55)$ & $(0.69)$ & $(0.85)$ & (1.69) & $(0.90)$ & $(0.35)$ & $(1.77)$ & $(0.93)$ & $(4.43)$ \\
\hline \multirow[t]{2}{*}{ Percent retired } & 0.515 & 0.712 & 0.583 & 0.497 & 0.563 & 0.292 & 0.578 & 0.655 & 0.353 & NA \\
\hline & $(0.008)$ & $(0.034)$ & $(0.038)$ & $(0.037)$ & $(0.056)$ & $(0.057)$ & $(0.013)$ & $(0.063)$ & $(0.030)$ & \\
\hline \multirow[t]{2}{*}{ Percent retired age $>59$} & 0.889 & 0.941 & 0.882 & 0.872 & NA & NA & 0.894 & NA & 0.804 & NA \\
\hline & $(0.008)$ & $(0.024)$ & $(0.034)$ & $(0.038)$ & & & $(0.011)$ & & $(0.042)$ & \\
\hline Observations & 3,743 & 177 & 168 & 181 & 80 & 65 & 1,441 & 58 & 255 & 18 \\
\hline Individuals & 1,032 & 54 & 42 & 44 & 23 & 25 & 364 & 23 & 73 & 6 \\
\hline Percent of immigrants & & $5 \%$ & $4 \%$ & $4 \%$ & $2 \%$ & $2 \%$ & $35 \%$ & $2 \%$ & $7 \%$ & $1 \%$ \\
\hline
\end{tabular}

Note: See the paper for further information about how the sample is created and variables are defined. NA are cells with too few observations to give an accurate estimate. 

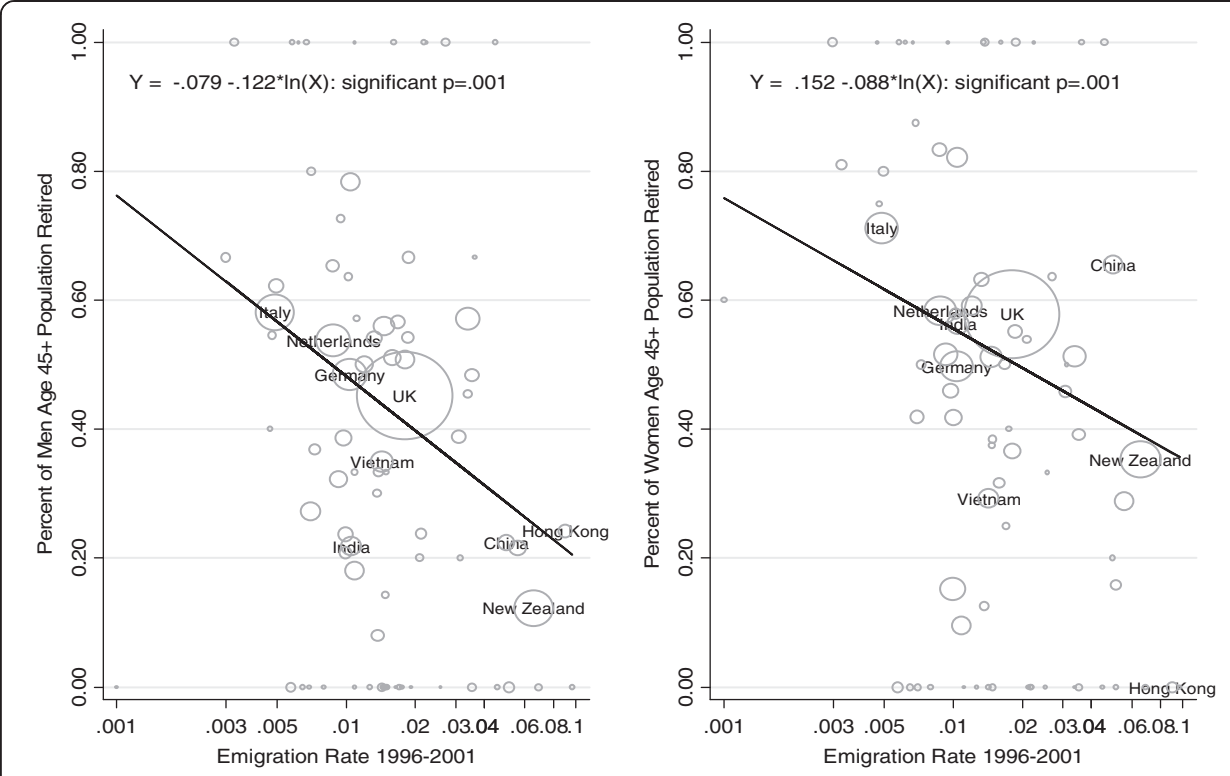

Figure 2 The relationship between retirement rates and emigration rates across countries by gender.

\section{The empirical relationship between return migration and retirement status}

\subsection{Basic regression analysis}

We now expand on the descriptive analysis in the previous section by using regression analysis to control for other socioeconomic characteristics that are related to the likelihood that individuals are retired and may also systematically differ by country of origin. We do this by estimating Equation (12) using a maximum likelihood probit regression model. We estimate three alternative specifications of this equation. The first controls only for the country of origin-specific return migration rate and indicator variables for
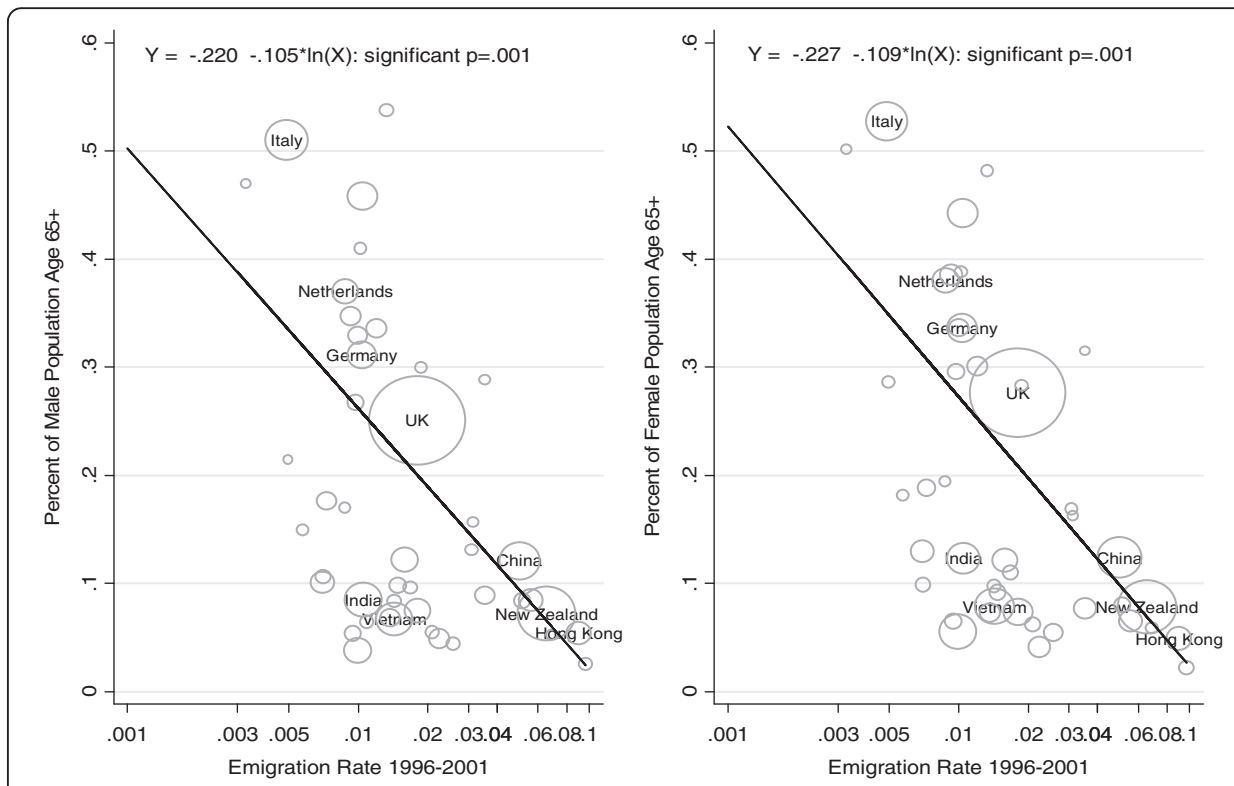

Figure 3 The relationship between population composition and emigration rates across countries by gender. 
the survey year and hence approximates the descriptive analysis in Figure 2. The demographic composition of different immigrant populations is closely related to their retirement patterns and may also be related to return migration rates. Thus, the second specification controls for each individual's age and years living in Australia (both as quadratics). The third specification adds additional controls for individuals' marital status, human capital (education, a quadratic in actual labor market experience, health status) household characteristics (number of children/adults) characteristics and whether or not they were born in an English language speaking country ${ }^{15}$. Marginal effects and standard errors for the impact of the return migration on the likelihood that an individual is retired are reported separately by gender in Table $2 .{ }^{16}$

The results indicate that, when we do not control for differences in individual and household characteristics, we find a strongly significant (at the 1 percent level) negative relationship between the incidence of retirement and return migration rates. Specifically, male immigrants (female immigrants) from origin countries with a 100 percent higher return migration rate are $12.8(8.7)$ percentage points less likely to be retired. ${ }^{17}$ The relationship between return migration and retirement status falls by a quarter for men, but remains unchanged for women when we control for each individual's age and years living in Australia. In both cases, the relationship remains strongly significant.

Finally, our third specification adds detailed controls for individual and household characteristics. Accounting for disparity in the socio-demographic characteristics of immigrants from different origin countries reduces the estimated relationship between return migration and retirement status. The effect is still sizable for men (5.1 percentage points), but is no longer significant at conventional levels. At the same time, the effect all but disappears for immigrant women suggesting that the link between their retirement status and the return migration rate of their fellow countrymen is largely explained by variation across origin countries in women's socio-demographic characteristics.

Table 2 Probit model of likelihood of being retired stratified by gender

\begin{tabular}{lccc}
\hline & (Marginal Effects and Standard Errors) & & \\
\hline & $(\mathbf{1})$ & (2) & (3) \\
\hline Log emigration rate & $-0.128^{* *}$ & $-0.087^{* *}$ & -0.051 \\
& $(0.038)$ & $(0.030)$ & $(0.034)$ \\
Percent declared retired & 0.426 & 0.426 & 0.426 \\
Pseudo R-squared & 0.021 & 0.474 & 0.594 \\
Observations & 4,055 & 4,055 & 4,055 \\
\hline & & Women & \\
\hline Log emigration rate & $-0.089^{* *}$ & $-0.090^{* *}$ & -0.027 \\
& $(0.031)$ & $(0.031)$ & $(0.038)$ \\
\hline Percent declared retired & 0.515 & 0.515 & 0.515 \\
Pseudo R-squared & 0.011 & 0.472 & 0.584 \\
Observations & 3,743 & 3,743 & $X, 743$ \\
\hline Controling for year & $X$ & $X$ & $X$ \\
Controling for age/yrs in Australia & & $X$ & $X$ \\
Controling for Indv/Hhold chars & & & $X$ \\
\hline
\end{tabular}

Note: Robust standard errors in parentheses that allow for clustering for at the disaggregate country level which includes accounting for clustering of individuals across time. ${ }^{* *} p<0.01,{ }^{*} p<0.05,+p<0.1$. See the paper for details about the included control variables. 


\subsection{Retirement status and return migration rates: variation across age-groups}

While we find mixed evidence of a relationship between return migration and retirement status among the immigrant population as a whole, our theoretical model indicates that the link between retirement status and return migration should be the strongest among immigrants who are closest to retirement age. We investigate this issue by re-estimating the third specification above allowing the relationship between return migration rates and retirement status to depend on how close immigrants are to qualifying for the Australian Age Pension. ${ }^{18}$ For conciseness we will refer to this as the retirement age.

Specifically, we estimate three specifications of the following modified version of Equation (12):

$$
\operatorname{Pr}\left(R_{i j}=1\right)=\operatorname{Pr}\left(X_{i j} \beta+Z_{j} \phi+Z_{j} A g e_{i j}^{*} \lambda+\varepsilon_{i j}>0\right) .
$$

In the first specification, $A g e_{i j}^{*}$ is defined as the number of years in absolute value an individual is away from the retirement age. In the second specification, the same definition is used but $A g e_{i j}^{*}$ is further interacted with whether an individual is younger or older than the retirement age. In the third specification, the main effect is now defined as being the relationship between return migration rates and retirement status of individuals within two years of the retirement age. There are separate interaction effects for being more than two but less than five years away from the retirement age and for being five or more years away from the retirement. Marginal effects and standard errors for the impact of the return migration on the incidence of retirement are reported separately by gender in Table 3 .

The results from the first specification indicate that-if the return migration rate of their fellow countrymen were 100 percent higher-male (female) immigrants aged 65 (63) would have a retirement rate that was 12.7 (8.4) percentage points higher. This relationship is statistically significant at the 1 percent level for men and at the 5 percent level for women. For every year that immigrants are younger or older than the retirement age, the strength of this relationship declines by 0.7-0.9 percentage points. Allowing the age pattern to differ for people younger and older than retirement (specification 2) halves the size of the relationship for retirement aged men and reduces by one-quarter the effect for retirement aged women. In neither case is this relationship statistically significant at conventional levels. If, rather than assuming a linear relationship, we instead categorize immigrants' age relative to the retirement age (specification 3), we find that for immigrant men aged 63 to 67 being from an origin country with a 100 percent higher return migration rate reduces the incidence of retirement by 9.4 percentage points. This effect is statistically significant at the 1 percent level. The relationship between return migration rates and retirement status for retirement aged women remains similar to that found in the second specification and again is not statistically significant at conventional levels.

The results for male immigrants are strongly supportive of our theoretical model. In particular, there is a significant negative relationship between the incidence of retirement and return migration rates for men at (or near) retirement age, the strength of which declines as immigrants move further away from the retirement age. The results for women are less conclusive and may reflect the fact that retirement and return 
Table 3 Probit model of likelihood of being retired by gender and age (marginal effects and standard errors)

\begin{tabular}{|c|c|c|c|}
\hline & (1) & $(2)$ & (3) \\
\hline & & Men & \\
\hline \multirow[t]{2}{*}{ Log emigration rate at retirement age (Age 65) } & $-0.127^{* *}$ & -0.064 & $-0.094^{* *}$ \\
\hline & $(0.038)$ & $(0.041)$ & $(0.034)$ \\
\hline \multirow[t]{2}{*}{ Log emigration rate * |age-65| } & $0.009^{* *}$ & & \\
\hline & $(0.003)$ & & \\
\hline \multirow[t]{2}{*}{ Log emigration rate * |age-65| if age $<65$} & & -0.003 & \\
\hline & & $(0.005)$ & \\
\hline \multirow[t]{2}{*}{ Log emigration rate * |age-65| if age $>65$} & & $0.027^{* *}$ & \\
\hline & & $(0.004)$ & \\
\hline
\end{tabular}

$\begin{array}{ll}\text { Log emigration rate * }(2<\mid \text { age- } 65 \mid<5) & 0.023^{* *}\end{array}$

(0.007)

$\begin{array}{ll}\text { Log emigration rate * }(\mid \text { age-65 } \mid>5) & 0.054^{* *}\end{array}$

\begin{tabular}{lccc} 
& & & $(0.010)$ \\
\hline P-Value on test of symmetric age effect & & 0.000 & \\
Pseudo R-squared & 0.599 & 0.605 & 0.600 \\
Observations & 4,055 & 4,055 & 4,055 \\
\hline & & Women & -0.053 \\
\hline Log emigration rate at retirement age (Age 63) & $-0.084^{*}$ & -0.061 & $(0.036)$
\end{tabular}

Log emigration rate * $\mid$ age-63| $0.007^{* *}$

(0.002)

$\begin{array}{lc}\text { Log emigration rate * } \mid \text { age-63| if age }<63 & 0.003 \\ \text { Log emigration rate * } \mid \text { age-63| if age }>63 & (0.003) \\ & 0.016^{* *} \\ & (0.005)\end{array}$

$\begin{array}{ll}\text { Log emigration rate } *(2<\mid \text { age-63|<5) } & 0.011\end{array}$

(0.011)

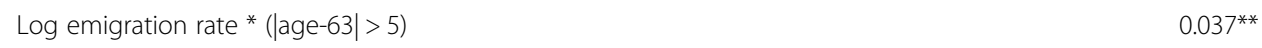

\begin{tabular}{llll} 
& & & $(0.011)$ \\
\hline P-Value on test of symmetric age effect & & 0.041 & \\
Pseudo R-squared & 0.587 & 0.588 & 0.588 \\
Observations & 3,743 & 3,743 & 3,743 \\
\hline
\end{tabular}

Note: Robust standard errors in parentheses that allow for clustering for at the disaggregate country level which includes accounting for clustering of individuals across time. ${ }^{* *} p<0.01,{ }^{*} p<0.05,+p<0.1$. All regressions include controls for individual and household characteristics and the year of observation.

migration decisions for them are more likely to the result of family rather than individual decisions.

To highlight the scale of the effect of return migration rates on retirement status, we calculate predicted retirement rates holding individuals' characteristics constant at the overall sample mean for retirement aged men and women (by gender) and varying return migration rates. We do this using the results from the third specification in Table 3 and report, in Table 4, the results for immigrants who are within two years of the retirement age and are from one of the nine countries discussed in Table 1. We also 
Table 4 Predicted probability of being retired for individual with mean characteristics from different countries by gender

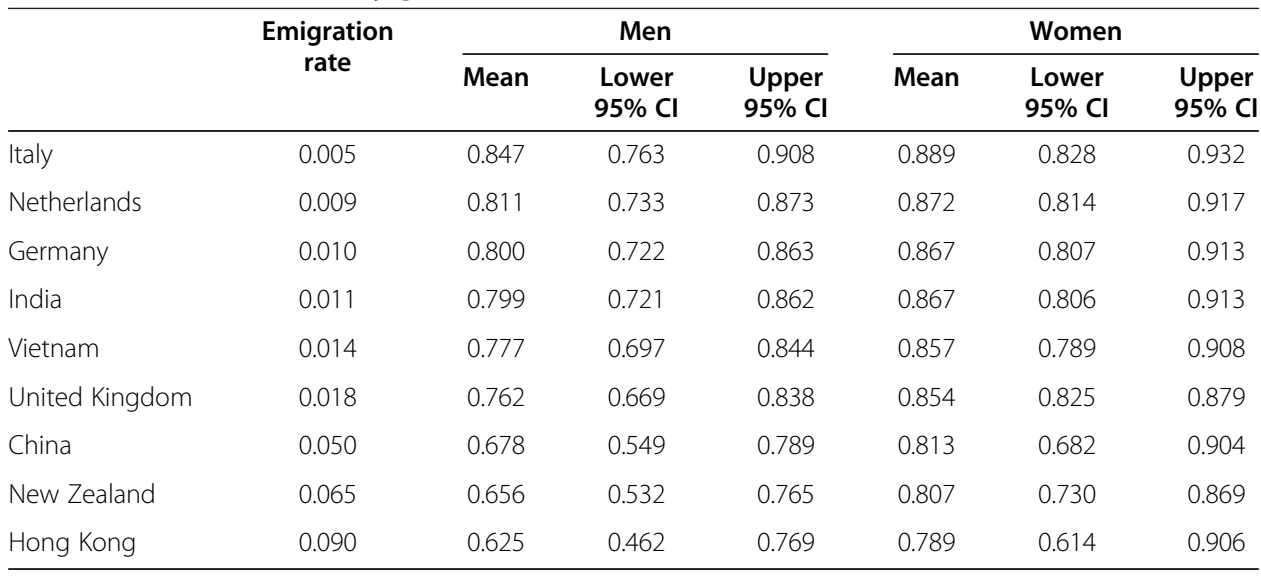

Note: Predicted probabilities are calculated using the coefficients from the third specification in Table 3, setting all characteristics to the sample mean by gender for individuals within 2 years of the retirement age besides the emigration rate, which is set to the appropriate level for a particular country.

present confidence intervals for these results calculated using the estimated standard error of each prediction.

Comparing the two extremes, we see that immigrant men (women) within two years of the retirement age from Hong Kong, which has a return migration rate of 9.0 percent, are 22.1 (10.0) percentage points less likely to be retired than otherwise equivalent immigrants from Italy, which has a return migration rate of 0.5 percent. The difference for men is significant just outside the 5 percent level, while the difference for women is not significantly different at conventional levels. This disparity implies that the national-origin mix of the immigrant inflow has important implications for the extent of return migration as well as for the retirement status (and age structure) of the immigrant population.

\section{Conclusions}

This paper analyzes the relationship between immigrants' retirement status and the prevalence of return migration from Australia to their country of origin. Our focus is not on estimating a behavioral model of individuals' retirement decisions, but rather on assessing the way in which the potential costs and benefits of return migration (as reflected in country-specific emigration rates) affect the retirement status of immigrants. Understanding this relationship is important because immigrants' decisions about when to retire and where to spend their retirement years drives the extent to which immigrant aging will result in an increased demand for health care or old-age pensions.

Our theoretical model demonstrates that under reasonable conditions the incentives to return migrate are greatest at retirement implying that there is a direct link between the prevalence of return migration among and the retirement status of different immigrant populations. Consistent with this model, we estimate a negative relationship between the immigrants' retirement status and the return migration rate of their fellow countrymen. As theory suggests, this link is strongest for immigrants who are at (or near) retirement age.

These results point to several important policy conclusions. First, as return migration rates vary substantially across sending countries, it is also the case that the age structure and composition of the domestic labor force in the years ahead rests 
fundamentally on the national origin mix of today's immigration flow. In short, immigrant selection policies have direct consequences for the funding of old-age pensions. Moreover, institutional arrangements surrounding the eligibility for citizenship, access to (and portability of) pensions, the provision of health care, etc. are likely to affect the net benefits to return migration and will therefore have far reaching consequences for the age composition of immigrant populations. Most of these relationships have received little attention and are not yet well understood. Modeling the linkages between return migration and retirement status (as we have done here), however, provides a useful way of beginning to think about the complex relationships between a range of domestic policies and demographic transitions within the immigrant population.

At the same time, these results leave open a number of important questions for future research. In particular, while some researchers have linked return migration to the incentives to accumulate savings or to send remittances (e.g. Galor and Stark 1990; Dustmann 1997b; Stark et al. 1997), it would be useful to understand how the potential for return migration is linked to the specific ways that immigrants fund their retirement. It seems sensible to expect that immigrants who intend to return home will have strong incentives to diversify their risk by saving both at home and abroad (Dustmann 1997b; Osili 2007). But what does this imply about the types of assets that immigrants hold? To what extent are decisions about home ownership or financial assets driven by expectations regarding return migration? Answers to these questions are important because consumption expenditures depend not only on wealth levels, but also on the composition of wealth, and because assets differ in terms of their expected rates of return, riskiness, and liquidity leading them to serve different functions in providing for a household's financial security (Cobb-Clark and Hildebrand 2009).

Finally, we need to know more about gender differences in immigrants' patterns of retirement and return migration. Making progress in this area is likely to require a household perspective of the return migration decision similar to that used to understand the initial immigration process (Mincer 1978). Our results, for example, point to a much closer relationship between the level of return migration and the retirement status of immigrant men. This may suggest that for many women the decision to return migrate-like the initial decision to immigrate-is based on family (rather than individual) returns. Moreover, women's retirement also needs to be understood in a household context. Specifically, we need to know more about the ways in which expectations regarding return migration, cultural differences in attitudes towards women, gender differences in assimilation profiles, etc. lead the age profile of retirement to differ for immigrant men and women.

\section{Endnotes}

${ }^{1}$ Most demographic projections of the effect of immigration on structural aging assume a constant rate of return migration, ignoring variation in return migration rates across source countries or across the life cycle. Rendall and Ball (2004) are an exception.

${ }^{2}$ Estimates suggest, for example, that between 20 and 50 percent of legal immigrants to the United States emigrated to another country in the 1960s and 1970s (Jasso and Rosenzweig 1982; Warren and Peck 1980). See Dustmann and Weiss (2007) for a review of the evidence on the magnitude of return migration. 
${ }^{3}$ Estimating the model at the individual level also allows us to control for individual heterogeneity in retirement decisions that relates to a person's age, years since first arrival in Australia, years of actual work experience, education, marital status, household composition, health status and whether they were born in an English speaking country.

${ }^{4}$ Borjas and Bratsberg (1996) conclude that return migration intensifies the selection associated with the initial immigration process.

${ }^{5}$ The exception is Dustmann and Kirchkamp (2002) who develop a theoretical model of the joint decision between labor supply behavior in both the host and origin country and the optimal time spent in the host country. However, they do not explicitly examine the interdependence of retirement and emigration decisions.

${ }^{6}$ This potential for return migration may provide a partial explanation for nativity differences in retirement expectations (Cobb-Clark and Stillman 2009).

${ }^{7}$ See Hill (1987) who adopts a similar approach.

${ }^{8}$ The assumption that consumption is cheaper in the origin country is needed in this simple model to generate return migration after retirement, but more generically immigrants may instead desire to emigrate because the marginal utility of leisure is higher in the origin country perhaps for cultural or familial reasons.

${ }^{9}$ We ignore the effects of time discounting for simplicity.

${ }^{10}$ Note that this also accounts for clustering over time in the error-term for a particular individual. As discussed in Moulton (1990), statistical inference can be seriously misleading when a regressor is measured at a more aggregated level than the observations in a regression, unless the regression allows for clustering at this level.

${ }^{11}$ In particular, all non-employed respondents were asked "Have you retired (completely) from the workforce." Response categories include: yes, no, and never worked.

${ }^{12}$ This is out of a total non-aboriginal sample meeting the same criteria of 7,271 individuals, hence the proportion of the sample which is foreign-born is 29.6 percent. This is higher than in the overall Australian population because of the older age group being examined.

${ }^{13}$ See http://wwww.immi.gov.au and http://www.infrastructure.gov.au for more information.

${ }^{14}$ Taiwan has the highest emigration rate in our sample at 0.097 , but there are only 9 immigrants from Taiwan in HILDA as opposed to 51 from Hong Kong, thus we focus on Hong Kong when making comparisons.

${ }^{15}$ Specifications are as follows. Model 1: the $\log$ of the return migration rate (see equation (13)) and indicator variables for waves 2-5. Model 2 also includes: a quadratic in age and a quadratic in years since first arrival in Australia. Model 3 further includes: a quadratic in years of actual work experience; indicator variables for having finished year 12, having a vocational certificate, having a tertiary degree; and being currently married (or cohabitating) as well as the length of this relationship; the number of individuals aged 0-15, 16-20 and 21 plus in the household; indicators for good, average, fair/poor, or missing self-reported health status; and an indicator variable for being born in an English speaking country. The English-speaking background countries are the United Kingdom, Ireland, United States, Canada, New Zealand and South Africa. Alternative results from a model of non-employment (rather than declared retirement) are substantially the same and are reported in Additional file 2. Full results from all regression models are available by request from the authors. 
${ }^{16}$ All estimation is performed in STATA 10. Standard errors are calculated using the delta method accounting for clustering on country of birth. This also controls for clustering of individuals across time.

${ }^{17}$ Recall that return migration rates range from 0.005 for Italy to 0.09 for Hong Kong hence a doubling of the emigration rate is well within the variation observed in the data.

${ }^{18}$ Although the institutional details of employer-provided pension plans can vary, Australian men (both citizens and permanent residents) qualify for the Age Pension provided by the Australian government at age 65 , while Australian women born before June 30, 1944 qualify at age 63. See www.centrelink.gov.au.

\section{Additional files}

Additional file 1: Characteristics by gender and immigration status.

Additional file 2: Probit model of likelihood of being not employed (marginal effects and standard errors).

\section{Competing interests}

The IZA Journal of Migration is committed to the IZA Guiding Principles of Research Integrity. The authors declare that they have observed these principles.

\section{Acknowledgements}

This paper uses confidentialized unit record file data from the Household, Income and Labour Dynamics in Australia (HILDA) survey. The HILDA Project was initiated and is funded by the Department of Families, Housing, Community Services, and Indigenous Affairs (FaHCSIA) and is managed by the Melbourne Institute of Applied Economic and Social Research (MIAESR). Much of this paper was written while Stillman was visiting the Chair for Statistics and Empirical Economic Research at the University of Zurich. Their wonderful hospitality was much appreciated. We also thank seminar audiences at the Korean Institute of Public Finance, Università Ca' Foscari, IZA, and Heriot-Watt University for comments, as well as those from an anonymous referee and the editor, Corrado Giulietti. This paper was presented at the IZA and Center on Human Capital Workshop on Migration and Human Capital in Bonn 23/24 May 2013. The Workshop was organized in collaboration with the Journal of Human Capital and the IZA Journal of Migration. The findings and views reported in this paper are those of the authors and should not be attributed to FaHCSIA or MIAESR. Responsible editor: Corrado Giulietti

\section{Author details}

${ }^{1}$ Melbourne Institute of Applied Economic and Social Research, University of Melbourne, Parkville, VIC 3010, Australia. ${ }^{2}$ Department of Economics, University of Otago, Po Box 56, Dunedin, New Zealand.

Received: 15 July 2013 Accepted: 30 September 2013

Published: 07 Nov 2013

\section{References}

Anderson GF, Hussey PS (2000) "Population aging: a comparison among industrialized countries". Health Aff 19(3):191-203 Australian Bureau of Statistics (ABS) (undated) Birthplace of individual by sex, counts of persons for Australia, 2001 census classification counts, 20220th edn. Commonwealth of Australia, Catalogue, downloaded at www.abs.gov.au

Australian Bureau of Statistics (ABS) (2007a) Country of birth of person (Full classification list) by sex, 2006 census of population and housing. Catalogue No. 2068.0 - 2006 Census Tables. Commonwealth of Australia, Canberra Australia. Available at: www.abs.gov.au.

Australian Bureau of Statistics (ABS) (2007b) Country of birth of person by age by sex, 2006 census of population and housing. Catalogue Cat. No. 2068.0 - 2006 Census Tables. Commonwealth of Australia, Canberra Australia. Available at: www.abe.gov.au.

Bauer TK, Sinning M (2011) "The savings behavior of temporary and permanent migrants in Germany". J Popul Econ 24 (2):421-449, CG3

Bermingham JR (2001) Immigration: not a solution to problems of population decline and aging. J Interdiscip Stud 22 (4):355-363

Bijak J, Kupiszewska D, Kupiszewski S, Katarzyna A, Kicinger A (2007) Population and labour forces projections for 27 European countries, 2002-2052: impact of international migration on population ageing. Eur J Popul 23:1-31

Boersch-Supan A (2003) "Labor market effects of population aging". Labour 17:5-44

Borjas G, Bratsberg B (1996) "Who leaves? The outmigration of the foreign-born". Rev Econ Stat 78(1):165-176

Cobb-Clark DA, Hildebrand VA (2009) "The Asset portfolios of native-born and foreign-born Australian households". Eco $\operatorname{Rec} 85(268): 46-59$

Cobb-Clark DA, Stillman S (2009) "The retirement expectations of middle-aged individuals". Eco Rec 85(269):146-163

Constant A, Massey DS (2002) "Return migration by German guestworkers: neoclassical versus new economic theories". Int Migr Rev 40(4):5-38, CG5

De Coulon A, Wolff FC (2006) "The location of immigrants at retirement: stay/return or 'Va-et-Vient'?" Institute for the Study of Labor (IZA) Discussion Paper 2224 Bonn Germany 
Department of Immigration and Citizenship (2007) Emigration 2006-07. Commonwealth of Australia, Australia. ISBN 1324-3411

Djajić S (1989) "Migrants in a guest-worker system". J Dev Econ 31:327-339

Dustmann C (1997a) Differences in the labor market behavior between temporary and permanent migrant women. Labour Econ 4:29-46

Dustmann C (1997b) "Return migration uncertainty and precautionary savings". J Dev Econ 52:295-316

Dustmann C (1999) "Temporary migration, human capital and language fluency of migrants". Scand J Econ 101 (2):297-314

Dustmann C (2003a) Children and return migration. J Popul Econ 16:815-830

Dustmann C (2003b) "Return migration wage differentials, and the optimal migration duration". Eur Econ Rev 47:353-369

Dustmann C (2008) "Return migration, investment in children, and intergenerational mobility: comparing sons of foreign and native born fathers". The Journal of Human Resources 43(2):299-324

Dustmann C, Kirchkamp O (2002) "The optimal migration duration and activity choice after re-migration". J Dev Econ 67:351-372

Dustmann C, Weiss Y (2007) "Return migration: theory and empirical evidence from the UK". Br J Ind Relat 45(2):236-256

Galor O, Stark O (1990) "Migrants' savings, the probability of return migration and migrants' performance". Int Econ Rev 31(2):463-467

Galor O, Stark O (1991) "The probability of return migration migrants' work effort, and migrants' performance". J Dev Econ 35:399-405

Gruber J, Wise DA (2001) "An international perspective on policies for an aging society". National Bureau of Economic Research (NBER) Working Paper W8103 Cambridge Massachusetts

Hill JK (1987) Immigrant decisions concerning duration of stay and migratory frequency. J Dev Econ 25:221-234

Holzmann R (2005) "Demographic alternatives for aging industrial countries: increases total fertility rate, labor force participation, or immigration. Institute for the Study of Labor (IZA) Discussion Paper 1885 Bonn Germany

Jasso G, Rosenzweig M (1982) Estimating the emigration rates of legal immigrants using administrative and survey data: the 1971 cohort of immigrants to the United States. Demography 19:279-290

Merkle L, Zimmermann KF (1992) "Savings remittances and return migration". Econ Lett 38:77-81

Mincer J (1978) Family migration decisions. J Polit Econ 86:749-773

Moulton B (1990) An illustration of a pitfall in estimating the effects of aggregate variables on micro units. Rev Eco Stat: 72(2):334-338

Osili UO (2007) Remittances and savings from international migration: theory and evidence using a matched sample. J Dev Econ 83:446-465

Rendall MS, Ball DJ (2004) "Immigration, emigration and the ageing of the overseas-born population in the United Kingdom". Popul Trends 116:18-27, Summer

Sinning M (2011) Determinants of savings and remittances: empirical evidence from immigrants to Germany". Review of Economics of the Household 9(1):45-67

Stark O, Helmenstein C, Yegorov Y (1997) "Migrants' savings purchasing power parity, and the optimal duration of migration". Int Tax Public Financ 4:307-324

United Nations (UN) (2001) "Replacement migration: is it a solution to declining and ageing populations? Department of Economic and Social Affairs, Population Division, New York

Warren R, Peck JM (1980) Foreign-born emigration from the United States. Demography 17:71-84

Wooden M, Friden S, Watson N (2002) "The household income and labour dynamics in Australia (HILDA) survey: wave 1". Aust Eco Rev 35(3):339-348

10.1186/2193-9039-2-20

Cite this article as: Cobb-Clark and Stillman: Return migration and the age profile of retirement among

immigrants. IZA Journal of Migration 2013, 2:20

\section{Submit your manuscript to a SpringerOpen ${ }^{\circ}$} journal and benefit from:

- Convenient online submission

- Rigorous peer review

- Immediate publication on acceptance

- Open access: articles freely available online

- High visibility within the field

- Retaining the copyright to your article

Submit your next manuscript at $\boldsymbol{\sim}$ springeropen.com 